\title{
Methylphenidate treatment of adult ADHD patients improves the degree of ADHD severity under routine conditions
}

\author{
Wolfgang Retz ${ }^{1} \cdot$ Michael Rösler ${ }^{2} \cdot$ Roland Fischer $^{3} \cdot$ Claudia Ose $^{4} \cdot$ Richard Ammer $^{3,5}$ (-)
}

Received: 29 November 2019 / Accepted: 11 May 2020 / Published online: 3 September 2020

(c) The Author(s) 2020

\begin{abstract}
Attention-deficit hyperactivity disorder (ADHD) is associated with substantial personal and social impairments. Besides psychosocial interventions, current guidelines recommend a therapy with methylphenidate (MPH). This prospective, noninterventional study aims to investigate the efficacy and tolerability of MPH treatment of adult ADHD patients in a real-world setting. 468 adult patients with newly diagnosed ADHD were observed for 12-14 weeks. Primary efficacy endpoint was the clinical global impression (CGI) by the physician. Secondary endpoints comprise patient evaluation (Wender-Reimherr selfreport, WR-SR), safety, tolerability, and dosage of MPH. With a mean daily dose of $35.8( \pm 17.0) \mathrm{mg} \mathrm{MPH}$, the population of patients being severely/most extremely ill or markedly ill decreased by $64 \%$ and $61 \%$, respectively. According to physicians' assessment (CGI), $74.5 \%$ of patients were identified as treatment responders. The total score of patient-based assessment (WR-SR) improved by $23.5 \%$ (50.1 \pm 40.3 points) with the most profound improvement in attention deficit $(-30.0 \%)$, disorganization $(-26.6 \%)$, and hyperactivity / unrest $(-23.3 \%)$. Self-evaluation revealed a responder rate of $35.4 \%$. In summary, MPH treatment improves the degree of ADHD severity under routine conditions. In addition, activities of daily living were facilitated when taking MPH. The rather poor responder rates determined by patient assessment as well as the comparatively low applied mean daily dose of $35.8 \mathrm{mg}$ (median $40 \mathrm{mg}$ ) indicate sub-optimal dosing under routine conditions, not exploiting the full beneficial therapeutic potential of MPH.
\end{abstract}

Keywords Methylphenidate $\cdot$ ADHD therapy $\cdot$ Dosage $\cdot$ Efficacy $\cdot$ Tolerability $\cdot$ Symptoms relief

\section{Introduction}

Richard Ammer

richard.ammer@ukmuenster.de

Michael Rösler

Michael.Roesler@uks.eu

1 Klinik für Psychiatrie und Psychotherapie, Universitätsmedizin Mainz, Mainz, Germany

2 Institut für Gerichtliche Psychologie und Psychiatrie, Universitätsklinikum des Saarlandes, Kirrberger Straße, 66421 Homburg/Saar, Germany

3 MEDICE Arzneimittel Pütter GmbH \& Co. KG, Iserlohn, Germany

4 Institut für Medizinische Informatik, Zentrum für Klinische Studien Essen, Universitätsklinikum Essen, Biometrie und Epidemiologie, Essen, Germany

5 Klinik für Innere Medizin, Universitätsklinikum Muenster, Muenster, Germany
Attention-deficit hyperactivity disorder (ADHD) is a mental disorder associated with various personal and social impairments (Kabisch et al. 2011) and represents the most prevalent disorder found in childhood and adolescence with a prevalence of 4-7\% (Spencer et al. 2007), which persists into adulthood in $65 \%$ of cases (Faraone et al. 2006). In Germany, up to $4.7 \%$ of adults suffer from ADHD (Ebert et al. 2003) with typical symptoms such as inattention, disorganization, impulsivity, agitation, distractibility, mood fluctuations, and poor planning capabilities (Faraone et al. 2006; Erskine et al. 2016; Fields et al. 2017). For adequate treatment, current guidelines recommend a multi-modal approach including psycho-social and pharmaco-therapeutic interventions (BfArM 2003; Medice 2017). In pharmacotherapy, MPH is recommended as first (BfArM 2003; S3 2018) or co-first line medication (NICE 2018) as its efficacy has been proven not only in children, but also in adults with ADHD in many randomized, placebo-controlled studies 
(RCTs) (Bottelier et al. 2017; Chobanian et al. 2003; Kessler et al. 2007; Wender et al. 1985; Rösler et al. 2009, 2013, 2005; Spencer et al. 1995; Retz et al. 2012).

RCTs with a high level of evidence and a low risk for systematic flaws represent the gold standard for evaluating efficacy and tolerability of a drug (Harbour and Miller 2001). Precise criteria for inclusion and exclusion of patients assure a relatively homogenous study population of patients recruited with comparable patient characteristics, demographic data, burden of disease, co-morbidities, and co-medication (Adler 2008), but frequently question the transferability of study results to clinical routine practice.

Non-interventional studies (NIS), in contrast, investigate efficacy and safety of a drug in a very heterogeneous group of patients and allow judgment under real conditions seen in routine clinical practice (Röhrig et al. 2009). With a usually large number of patients included, also less common adverse events can be documented. So far, there are only limited data for MPH in adults with ADHD collected from non-interventional studies. Thus, the aim of this NIS was to gather further insights in the use of MPH and its efficacy and tolerability of MPH in adults with newly diagnosed ADHD. Medikinet ${ }^{\circledR}$ adult was the first MPH product in Germany approved for treating adults with ADHD, with a modified release profile and investigated in RCTs EMMA and QUMEA (Retz et al. 2012; Rösler et al. 2009).

In the presented multi-center cohort study, we investigate a large, heterogeneous set of patients and the effect of MPH on both ADHD symptoms (hyperactivity, impulsivity, inattention) and emotional factors such as coping with stress and mood instabilities.

\section{Patients and methods}

\section{Study design}

We present a prospective, non-interventional study according to $\$ 4,23(3)$ German drug law (AMG) supported by a positive vote by the ethics committee Saarland. Patients included had a newly diagnosed ADHD and were eligible for pharmacotherapy with methylphenidate (MPH) based on the assessment of the treating physician. Diagnosis of ADHD according to DSM-IV was validated by applying the screening test with self-evaluation ASRS-V1.1 and a standardized interview IDA (integrated diagnosis of ADHD in adults) (Katzman et al. 2017; Retz et al. 2013).

Pharmacotherapy with MPH was in line with the approved label (Medice 2017) stressing careful dose titration. Duration of observation was 12-14 weeks (mean $3.3 \pm 1.6$ months) with an initial examination at the day of inclusion (visit 1) and a final examination at the end (visit 2). Parameters recorded were vital signs, extend of ADHD core symptoms and ADHD associated symptoms such as emotional dysregulation, level of disorganization, and social adaptiveness by applying Wender-Reimherr self-Evaluation (WR-SB, visit 1 and 2). Additionally, data on history, diagnosis and therapy (visit 1 ) as well as change in clinical global impression (CGI), dosing, tolerability (visit 2) were documented.

Primary endpoint was efficacy-based physician's assessment CGI. Secondary endpoint was patient self-evaluation (WR-SB) as well as tolerability and dosage of MPH.

\section{Efficacy assessment}

Efficacy of treatment with MPH was assessed by means of CGI measures, a 7-step scale for severity of symptoms (CGI$\mathrm{S}, 1=$ no disorder, $7=$ severe disorder) and a 7 -step scale for improvement of symptoms (CGI-I, $1=$ impressive improvement, $4=$ no improvement, $7=$ strong deterioration).

Efficacy was also measured by patient self-assessment using Wender-Reimherr self-evaluation (WR-SB) which applies a five-step scale both for classical criteria inattention, hyperactivity, impulsivity and additional symptoms typical for adults such as disorganization, emotional dysregulation and problems in social adaptiveness. The scale comprises 53 items addressing 10 categories. All items need to be assessed in a 5-step Likert scale $(1=$ does not apply to me at all; $5=$ applies to me very well) resulting in values between 53 (low burden of disorder) to 265 points (high burden). Responders were defined as patients experiencing a very good to good improvement in CGI $(\mathrm{CGI}-\mathrm{I}<2)$ or reduction in WR-SB by $>30 \%$.

\section{Safety assessment}

Endpoints for safety were vital parameters and overall tolerability. Vital signs (blood pressure, heart rate, weight, BMI, and appetite) were documented in both visits and after changes in dosing of MPH. In visit 1, additional characteristics (age, sex, type of ADHD, co-morbidities, co-medication and initiation of MPH treatment) were recorded. Over the course of the study, related and non-related adverse events and suspected events were documented and reported if severe.

\section{Statistics}

Descriptive statistics comprises absolute, relative and adjusted relative frequencies, multiple recordings, cross tables, means, standard deviations, median, and range. Wilcoxon rank-test was applied for calculating changes in CGI overall and sub-scores, WR-SB using software SAS version 9.4 running on a Windows 7TM personal computer. Comedication was coded according to WHO-ATC. Coding of 
adverse events and co-morbidities followed MedDRA version 17.0.

\section{Results}

\section{Patient characteristics}

468 adult ADHD patients from 126 sites (mean 3.8 \pm 4.0 patients per site, range $2-7$ patients per site) were followed for $3.3 \pm 0.5$ months in average. The age of patients (57.9\% male) ranged from 18 to 71 years with a mean of $32.4 \pm 10.8$ years.

The type of ADHD, was most frequently classified as combined type in 209 patients, $44.7 \%$; inattentive type in 162 patients $(34.6 \%)$ and hyperactive-impulsive type in 43 patients $(9.2 \%)$. Co-morbidities were found in 246 patients, $52.6 \%$ of the population. Frequently, patients suffered from psychiatric disorders (197 patients, 42.1\%) with depression the lead co-morbidity (129 patients, $27.6 \%$ ) (Table 1).

Co-medication prescribed consisted mainly of antidepressants (113 patients, 24.2\%), neuroleptics (24 patients, $5.1 \%$ ), and for somatic indications, thyroid hormone replacement led in 3.4\% (16 patients). Overall, 165 patients (35.4\%) were on co-medication during the course of the study and 102 patients (21.8\%) received psycho-social non-pharmacological add-on therapy.

\section{Dosing}

Overall, data on initial dosing of MPH through last dosage were obtained from 411 patients. Mean of initial first dosing was $18.4( \pm 12.7$; median 10.0$) \mathrm{mg} /$ day, equivalent to $0.23( \pm 0.16) \mathrm{mg} / \mathrm{kg}$ bodyweight. Last dosage at visit 2 was $35.8( \pm 17.0$; median 40.0$) \mathrm{mg} /$ day, equivalent to 0.45 $( \pm 0.21) \mathrm{mg} / \mathrm{kg}$ bodyweight. At both visits, minimal dosage was $5.0 \mathrm{mg} /$ day, maximal dosage was $80.0 \mathrm{mg} /$ day (Fig. 1).

\section{Add-on psycho-social non-pharmacological therapy}

In these 468 patients included in the study, 366 patients had no explicit add-on non-pharmacological intervention prescribed. In 102 patients, 122 non-pharmacological interventions were prescribed as add-on therapy with mainly psychotherapy in $30.3 \%$ of cases, behavioural therapy in $22.1 \%$ and communication therapy in $16.4 \%$ and ergotherapy in 9.8\% (Table 2).

\section{Efficacy assessed by physician and patient}

At visit 1 , severity of disorder was classified by treating physician as "very severe" or "severe" according to CGI in 62 patients (14.2\%), "marked" in 227 patients $(52.1 \%)$,
Table 1 Patient characteristics

\begin{tabular}{|c|c|c|}
\hline & \multicolumn{2}{|c|}{ Number of patients } \\
\hline & Absolute & In \% \\
\hline \multicolumn{3}{|l|}{$\operatorname{Sex}(n=468)$} \\
\hline Male & 271 & 57.91 \\
\hline Female & 197 & 42.09 \\
\hline \multicolumn{3}{|l|}{ Age $(n=462)$} \\
\hline Mean & 32.49 years & \\
\hline Min-Max & $18-71$ years & \\
\hline \multicolumn{3}{|l|}{ Weight $(n=460)$} \\
\hline Mean & $79.8 \mathrm{~kg}$ & \\
\hline Min-Max & $54-97 \mathrm{~kg}$ & \\
\hline \multicolumn{3}{|l|}{ BMI $(n=460)$} \\
\hline Mean & $24.95 \mathrm{~kg} / \mathrm{m}^{2}$ & \\
\hline \multicolumn{3}{|l|}{ Diagnosis (IDA, $n=468$ ) } \\
\hline ADHS in childhood & 11 & 2.35 \\
\hline ADHD, combined type & 209 & 44.66 \\
\hline ADHD, inattentive type & 162 & 34.62 \\
\hline ADHD, hyperactive-impulsive type & 43 & 9.19 \\
\hline No diagnosis & 43 & 9.19 \\
\hline \multicolumn{3}{|c|}{ Co-morbidities $(n=468$, incidence $>1.9 \%)$} \\
\hline Total & 246 & 52.56 \\
\hline Depression & 129 & 27.56 \\
\hline Anxiety & 17 & 3.63 \\
\hline Personality disorder & 15 & 3.21 \\
\hline Anxiety & 11 & 2.35 \\
\hline Social phobia & 11 & 2.35 \\
\hline Hypothyreosis & 10 & 2.14 \\
\hline Substance use disorder & 9 & 1.92 \\
\hline Hypertension & 9 & 1.92 \\
\hline \multicolumn{3}{|c|}{ Co-medication $(n=468$, incidence $>1.4 \%)$} \\
\hline Total & 165 & 35.26 \\
\hline Anti-depressants & 113 & 24.15 \\
\hline Neuroleptics & 24 & 5.13 \\
\hline Thyroid medication & 16 & 3.42 \\
\hline Antiepileptic agents & 9 & 1.92 \\
\hline COPD medication & 8 & 1.71 \\
\hline Other neurotropic medications & 7 & 1.50 \\
\hline
\end{tabular}

"moderate" in 117 patients (26.8\%), and "light" in 25 patients (5.7\%) (Fig. 2). At the end of the observation at visit 2 , the portion of (very) severely affected patients was reduced by $64 \%$, and by $61 \%$ in markedly affected patients. Overall, the severity of disorder was significantly improved over the course of the study.

According to physicians' assessments based on CGII, $74.5 \%$ of patients (318 patients) were classified as responders, of which 83 patients $(19.4 \%)$ were in "much better" and 235 patients $(55.0 \%)$ in a "clearly better" state (Fig. 3). Slight improvement was registered in 82 patients 


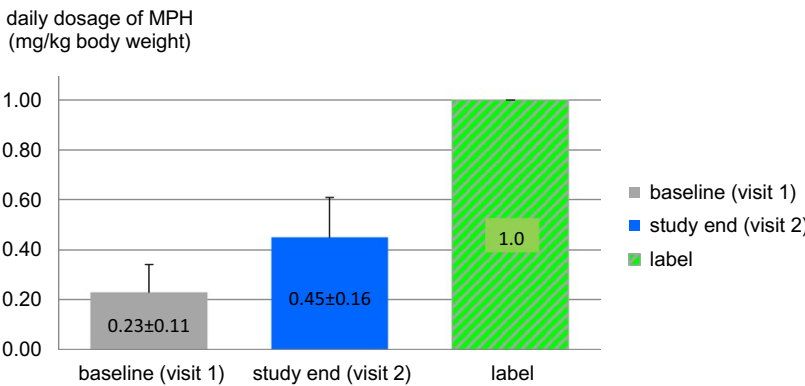

Fig. 1 Daily dosage of MPH at baseline (visit 1) and at study end (visit 2). Mean of initial first dosing was $18.4( \pm 12.7$; median 10.0) $\mathrm{mg} /$ day, equivalent to $0.23( \pm 0.11) \mathrm{mg} / \mathrm{kg}$ bodyweight. Last dosage at visit 2 was $35.8( \pm 17.0$; median 40.0$) \mathrm{mg} /$ day, equivalent to 0.45 $( \pm 0.16) \mathrm{mg} / \mathrm{kg}$ bodyweight. The approved label allows $1.0 \mathrm{mg} / \mathrm{kg}$ body weight

Table 2 Add-on psycho-social non-pharmacological therapy

\begin{tabular}{llll}
\hline & \multicolumn{3}{l}{ Number of patients } \\
\cline { 2 - 3 } & Absolute & In \% & In \% adjusted \\
\hline Intervention & & & \\
Pharmacological & 366 & 78.2 & \\
Add-on non-pharmacological & 102 & 21.8 & 100.0 \\
Non-pharmacological therapy & & & \\
Psychotherapy & 37 & 7.9 & 36.3 \\
Behavioral therapy & 27 & 5.8 & 26.5 \\
Communication therapy & 20 & 4.3 & 19.6 \\
Ergotherapy & 12 & 2.6 & 11.8 \\
Sports & 6 & 1.3 & 5.9 \\
Social therapy & 4 & 0.9 & 3.9 \\
Coaching & 3 & 0.6 & 2.9 \\
Relaxation & 3 & 0.6 & 2.9 \\
Family therapy & 2 & 0.4 & 2.0 \\
Day structuring & 2 & 0.4 & 2.0 \\
Drug counselling service & 1 & 0.2 & 1.0 \\
ADHD training & 1 & 0.2 & 1.0 \\
Drug addiction treatment & 1 & 0.2 & 1.0 \\
Group therapy & 1 & 0.2 & 1.0 \\
Day care & 1 & 0.2 & 1.0 \\
Professional re-integration & 1 & 0.2 & 1.0 \\
\hline
\end{tabular}

(19.2\%), no change was seen in 26 patients $(6.1 \%)$, and one patient $(0.23 \%)$ deteriorated.

Therapeutic efficacy (CGI-efficacy index) was assessed "very good" in 171 patients $(40.9 \%)$ with complete or nearly complete remission of all symptoms. It was reported that 176 patients $(42.1 \%)$ revealed significant improvement with partial remission of symptoms, a slight improvement requiring further treatment was seen in 60 patients (14.3\%), and 11 patients $(2.6 \%)$ were regarded as "unchanged" or "deteriorated" (Table 3 ).

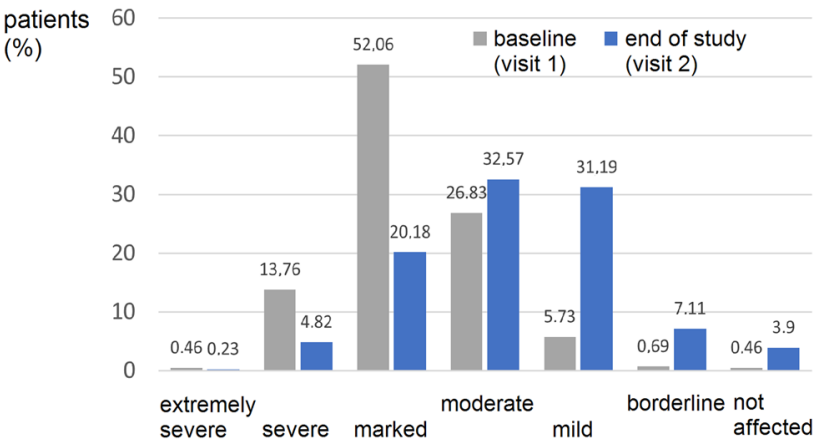

Fig. 2 Extent of disorder according to CGI severity scale. Patients were classified into seven categories (not affected to extremely severe) at the beginning (visit 1) and the end of the study (visit 2). Percentage of patients is plotted. Physicians' assessment showed a significant improvement from baseline to study end

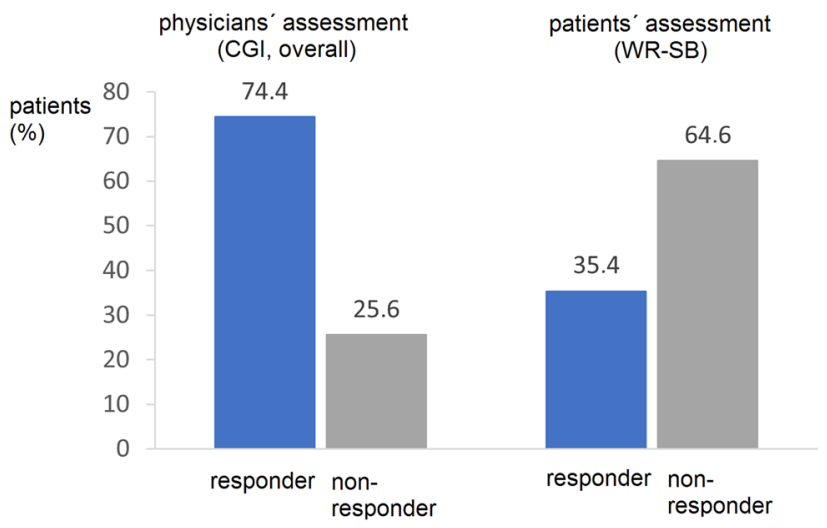

Fig. 3 Responder rates according to physicians' and patients' assessment. Plotted is the percentage of patients (in \%) who are classified as responders according to physicians' assessment (by means of CGI) or patients' assessment (by means of WR-SB). Physicians reported a higher portion of patients as responders in comparison to patients ( $75 \%$ vs. $35 \%)$

Patients' self-assessments based on WR-SB reported a significant improvement $(p<0.001)$ in the underlying subscorings (Fig. 4). The total score WR-SB had initially 203.4 $( \pm 37.6)$ points at visit 1 and improved under MPH medication by $50.1( \pm 40.3)$ points down to $153.4( \pm 40.2)$ points at visit 2 translating into a mean relative reduction of $23.5 \%$ and an improvement of symptom severity in adult patients.

According to patients' assessments, $35.4 \%$ of patients (146 patients) were classified as responders (Fig. 3). Multivariate analysis identified severity of disorder at the beginning of study as the main factor for the extent of symptom reduction. In consequence, the number of patients classifiable as responders was much higher in patients with severe or very severe symptoms (responder rate 50.8\%). The most obvious reductions were observed with item 
Table 3 Efficacy index

\begin{tabular}{|c|c|c|c|c|c|c|c|c|c|c|}
\hline \multirow[t]{3}{*}{ Therapeutic efficacy } & \multicolumn{10}{|c|}{ Adverse events } \\
\hline & \multicolumn{2}{|c|}{ None } & \multicolumn{2}{|c|}{ Irrelevant } & \multicolumn{2}{|c|}{ Relevant } & \multicolumn{2}{|c|}{ Dominating } & \multicolumn{2}{|c|}{ Total } \\
\hline & $n$ & $\%$ & $N$ & $\%$ & $n$ & $\%$ & $n$ & $\%$ & $n$ & $\%$ \\
\hline Excellent & 156 & 37.32 & 14 & 3.35 & 1 & 0.24 & 0 & 0 & 171 & 40.91 \\
\hline Moderate & 157 & 37.56 & 14 & 3.35 & 4 & 0.96 & 1 & 0.24 & 176 & 42.11 \\
\hline Slight & 52 & 12.44 & 6 & 1.44 & 1 & 0.24 & 1 & 0.24 & 60 & 14.35 \\
\hline Unchanged, worse & 8 & 1.91 & 0 & 0 & 3 & 0.72 & 0 & 0 & 11 & 2.63 \\
\hline Total & 373 & 89.23 & 34 & 8.13 & 9 & 2.15 & 2 & 0.48 & 418 & 100 \\
\hline
\end{tabular}

Depicted is therapeutic efficacy (very good, moderate, slight, and unchanged/worsened) in relation to adverse effects (none, irrelevant, relevant, and dominating) in absolute and relative patient numbers (4)

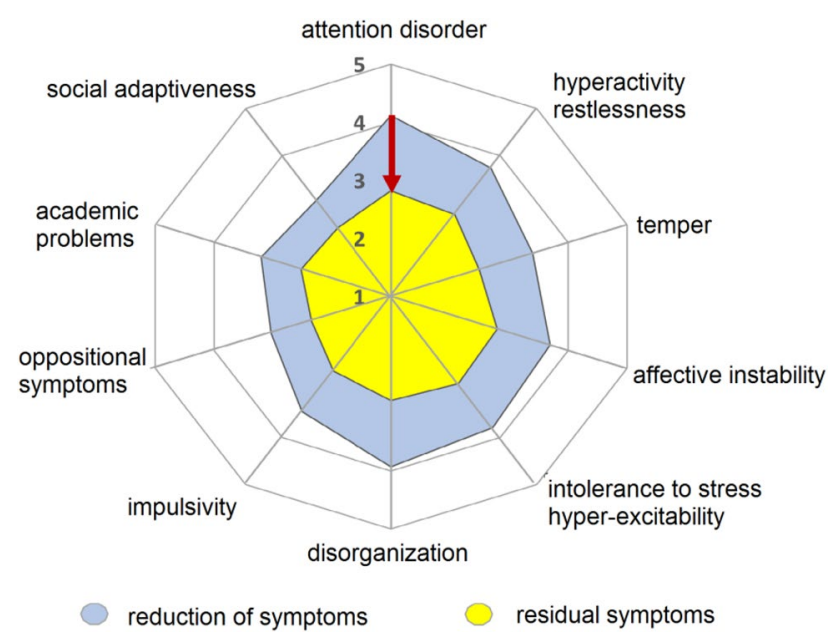

Fig. 4 Reduction of symptoms under treatment with methylphenidate according to patients' assessment (WR-SB). Extent of symptoms classified into ten criteria was documented at the beginning of the study (visit 1) depicted in blue, and at the end of the study (visit 2) as remaining residual symptoms (depicted in red) by means of a 5-step Likert scale (" $1=$ does not apply to me" to 5 ("applies to me very well"). The graph represents the mean values. In summary, there is a significant improvement of symptoms and their examined sub-scores and an improvement in the intensity and extent of symptoms in adults with ADHD treated with methylphenidate

attention disorder $(-30.0 \%)$, disorganization $(-26.6 \%)$, hyperactivity $(-23.3 \%)$, and poor stress resilience or hyper-excitability $(-23.0 \%)$. The total number of patients with a much better or better state of health was assessed in 318 patients $(74.5 \%)$. These patients were matching the definition of $30 \%$ improvement. In a multivariate analysis, the relation between potential demographic factors or patient characteristics such as sex, age, severity of disorder, BMI and response were analysed, but revealed no statistical significance ( $p=0.3265$, likelihood ratio test). The co-morbidity of depression showed a slight improved response $(p=0.0164)$. Highest impact on response rate had dosage of stimulants $(p=0.0012)$.
Table 4 Adverse events

\begin{tabular}{llll}
\hline & \multicolumn{2}{l}{ Number of } & \\
\cline { 2 - 4 } & $\mathrm{AE}$ & Patients & in $\%$ \\
\hline No AE & 0 & 417 & 89.1 \\
$\mathrm{AE}$ & 100 & 51 & 10.9 \\
non-severe AE & 99 & 50 & 98.0 \\
severe AE & 1 & 1 & 1.96 \\
Death & 0 & 0 & 0 \\
Type of AE (MedDRA & 17.0) & $n=468$. incidence $>0.3 \%$ & \\
Appetite reduced & & 8 & 1.71 \\
Headache & & 8 & 1.71 \\
Restlessness & & 5 & 1.07 \\
Tiredness & & 4 & 0.85 \\
Nausea & & 4 & 0.85 \\
Diarrhea & 3 & 0.64 \\
Hypertension & 3 & 0.64 \\
Palpitations & 3 & 0.64 \\
Dizziness & & 2 & 0.64 \\
Dyssomnia & 2 & 0.43 \\
Heart rate increase & 2 & 0.43 \\
Hyperhidrosis & & 2 & 0.43 \\
Dry mouth & & 2 & 0.43 \\
Abdominal pain & & & 0.43 \\
Tachycardia & & & \\
\hline
\end{tabular}

Depicted are number, type, and frequency of reported adverse events in absolute and relative frequencies

\section{Safety-adverse events}

In 417 patients (89.1\%), no adverse events were reported at all. In 51 patients (10.9\%), a total of 100 adverse events was documented, i.e. one to two events per patient. Most prevalent was reduced appetite and headache (eight patients each, $1.7 \%$ ), excitability (five patients, $1.1 \%$ ), tiredness, and nausea (four patients each, $0.9 \%$ ) (Table 4). In one patient $(0.23 \%)$, a severe event (relapse of polytoxicomania) was documented; however, it was classified as unlikely related to MPH. 
At visit 1, blood pressure measurements (JNC7 scheme, de Zwaan et al. 2012) were within normal range in 68 patients $(17.4 \%)$, were pre-hypertensive in 240 patients $(61.5 \%)$, a hypertension stage 1 or 2 in 82 patients $(21.0 \%)$. Mean measurement was $124.3 / 78.9( \pm 12.1 / 9.5) \mathrm{mmHg}$. An increase of $1.1 / 0.5( \pm 10.2 / 9.3) \mathrm{mmHg}$ at the end of the study was regarded clinically insignificant. In analogy, the small change in heart rate from $73.2( \pm 9.6)$ beats per minute at visit 1 to $75.3( \pm 9.9)$ beats per minute at visit 2 and the reduction of BMI from $25.1( \pm 4.7) \mathrm{kg} / \mathrm{m}^{2}$ to $25.0( \pm 5.5) \mathrm{kg} /$ $\mathrm{m}^{2}$ was also not clinically relevant. Only, a major portion of patients expressed being less hungry. Change in appetite was reported in 10 of 468 patients, 8 patients had a decrease in appetite, 1 patient experienced increased appetite, 1 patient was reported change in appetite. Of interest, decrease in appetite was only reported in patients diagnosed with the inattentive $(n=7)$ or the combined subtype $(n=1)$, but not in the hyperactive-impulsive subtype. Overall, MPH proved to be an effective and safe medication in the treatment of adults with ADHD.

\section{Discussion}

ADHD in adulthood is frequently associated with additional psychiatric disorders like depression and anxiety. If untreated, it leads to a higher risk of substance abuse and problems in social and professional life (Erskine et al. 2016). In comparison to children, the therapeutic options for adults are limited. In Germany, Medikinet ${ }^{\circledR}$ adult was approved in April 2011 as the first medication approved for pharmacotherapy of adult ADHD (Biederman et al. 2006). In the meantime, further methylphenidate preparations are available as well as noradrenalin re-uptake inhibitor atomoxetine.

The efficacy and safety of MPH in adult ADHD patients were shown in three randomized, double-blind, placebo-controlled trials, in EMMA (Rösler et al. 2009) and QUMEA (Retz et al. 2015) and COMPAS (Philipsen et al. 2015; Lam et al. 2019). While in these controlled studies, patients with comorbid psychiatric disorders or co-medication were mainly excluded, our observational study included such patients with psychiatric disorders and co-medication of multiple psycho-pharmacological agents. More than half of the study population (52.6\%) suffered from co-morbidities associated with ADHD and more than a third of patients were on co-medication $(35.3 \%)$. Our sample of patients included in our cohort was recruited from all over Germany: an unusually high number of centers $(n=126)$ was recruited by announcing to all adult psychiatric offices registered in the national society of psychiatry with an interest in ADHD $(n=1200)$ and asking to participate in the trial. The aim was to provide a representative sample of patients recruited in urban and rural areas and avoiding center effects with potential differences in diagnostic and treatment approaches. Thus, our sample had no selection bias and should perfectly represent the usual clientele of adult ADHD patients treated with MPH under real-life conditions.

Intake of MPH has shown no clinically relevant impact on blood pressure, heart rate, or body weight. The observed changes were minimal and clinically insignificant comparable to findings in RCTs (Rösler et al. 2009; Retz et al. 2012). With regard to adverse events, 99 of 100 findings collected during the study period were classified as non-severe and already known and listed in the label (Medice 2017). Only six patients discontinued due to adverse events. In comparison, in QUMEA (Retz et al. 2015), 151 adverse events were registered in 55 patients and in EMMA (Rösler et al. 2009) with 363 patients included 31 patients had to discontinue due to adverse events. In light of these findings, the number and portion of adverse events are relatively low in the study population of this observational study and medication with MPH under routine conditions can be regarded well tolerated and safe.

A recent study addressing prescription patterns of ADHD medications revealed that MPH was the number one medication among all age groups in line with current guidelines and official labels (Bachmann et al. 2017). Also other studies confirm the positive effect of MPH pharmacotherapy on various parameters: MPH reduces reactivity in the amygdala which translates into a positive effect in controlling emotional dysregulation, being a part of the limbic system which plays a relevant role in emotional control (Bouffard et al. 2003). MPH also leads to cognitive enhancement but does not completely normalize but supports psychotherapeutic measures (Fuermaier et al. 2017). In addition, MPH significantly reduces ADHD symptoms and improves everyday functioning and health-related aspects for quality of life (Rösler et al. 2013).

In addition, this study focused on changes in ADHD symptoms and social aspects related to MPH medication. According to physicians' CGI assessment in $74.5 \%$ of cases, CGI improved very much and much under MPH medication which was even higher than in the RCTs $(50 \%$ in QUMEA, $61 \%$ in EMMA). Therapeutic efficacy in relation to adverse events was reported as rated very good in $40.9 \%$ of patients at the end of the study, lower than the $60.1 \%$ cases reported in EMMA (Rösler et al. 2009). Still, $89 \%$ of patients continued MPH medication after the official study end, which clearly indicates a positive benefit-risk assessment and adverse effects not preventing continuation.

Patients also had to undertake self-ratings assessing changes pre- and post- treatment, including social factors and interpersonal problems with colleagues, employers, children and partners. In other words, associated aspects are regarded of high relevance in everyday functioning and quality of life (Harpin 2005; Kooij et al. 2004). 
In the observational study, aspects of social adoption were markedly improved under MPH medication. Patients reported a $23.5 \%$ improvement in burden of symptoms. $35.4 \%$ of patients classified themselves as treatment responders in their self-assessment lower than physicians' assessments; such discrepancy is generally known from everyday practice and has been reported in scientific literature. Of interest, a recent study revealed arousal regulation as a relevant predictor for stimulant therapy (Strauß et al. 2019). In our study, dosage of methylphenidate correlated positively with response rate. Of notice, daily dosage with $35.8 \pm 17 \mathrm{mg}$ MPH was relatively low in our study population. Given the positive dose-effect correlation for MPH (Spencer et al. 1995; our multivariate analysis), we see that therapeutic potential is not fully exploited in daily routine. This finding is of relevance: in randomized controlled trials which have frequently shown good treatment efficacy and good safety profile, the dosing is usually determined by a rigid study protocol. However, in real life such as seen in this observational study, dosing is rather low and matches with only moderate self-rated improvement (Fig. 3). This could be an explanation that the number of prescriptions for ADHD is rather low among adults as underlined by relevant indicators. In adults, diagnostic prevalence is $0.1 \%$ and a treatment prevalence is $0.05 \%$ with 570 thousand units prescribed with a mean dosage of $0.45 \mathrm{mg} / \mathrm{kg}$ BW (IQVIA 2019; Insight health 2019; Thome et al. 2019). In contrast, in children and adolescents, the reported diagnostic prevalence is $4.0 \%$ and a treatment prevalence exceeds $2.5 \%$ with 1583 thousand units prescribed with a mean dosage of $0.80 \mathrm{mg} / \mathrm{kg}$ BW (IQVIA 2019; Insight health 2019). Besides under-dosing, other explanations could be the insufficient level of prescribed non-pharmacological add-on therapy as only $21.8 \%$ received such multi-modal treatment or the rather new diagnostic entity and treatment options available for which continuous medical education is needed (Thome et al. 2019). Alternatively, from a different perspective, a reduced burden of disease in progressing age experienced by the patient or better coping strategies, and overall the still limited access to expert therapists as addressed in the recent RAABE study (Thome et al. 2019).

Overall, this observational study is limited by its noninterventional design and thus does not allow the evaluation of cause-effect relations. Nevertheless, the high number of patients included the study represents a comprehensive cross-sectional view in everyday clinical routine with significant findings.

\section{Conclusion}

Severity of ADHD is improved by MPH pharmacotherapy in routine clinical practice. This non-interventional study confirms the positive efficacy and safety profile of MPH for treating adults with ADHD in routine practice as already reported from RCTs (EMMA (Rösler et al. 2009) and QUMEA (Retz et al. 2012) and COMPAS (Philipsen et al. 2015; Lam et al. 2019)). Moreover, the study revealed positive effects on everyday functioning when treated with MPH. Important findings such as relatively low response rate reported in the patient self-assessment and markedly low daily dosage of $40 \mathrm{mg} /$ day indicate that dose titration is not fully exploited in routine practice and may lead to sub-optimal individualized treatment results. A more careful dose titration could further improve the positive benefit of MPH seen in routine care.

Acknowledgements Dr. Elmar Beck (ANFOMED applied research) performed the statistical analysis.

Funding Open Access funding provided by Projekt DEAL.

Open Access This article is licensed under a Creative Commons Attribution 4.0 International License, which permits use, sharing, adaptation, distribution and reproduction in any medium or format, as long as you give appropriate credit to the original author(s) and the source, provide a link to the Creative Commons licence, and indicate if changes were made. The images or other third party material in this article are included in the article's Creative Commons licence, unless indicated otherwise in a credit line to the material. If material is not included in the article's Creative Commons licence and your intended use is not permitted by statutory regulation or exceeds the permitted use, you will need to obtain permission directly from the copyright holder. To view a copy of this licence, visit http://creativecommons.org/licenses/by/4.0/.

\section{References}

Adler LA (2008) Epidemiology, impairments, and differential diagnosis in adult ADHD: introduction. CNS Spectr 13(8 Suppl 12):4-5

Bachmann CJ, Philipsen A, Hoffmann F (2017) ADHD in Germany: trends in diagnosis and pharmacotherapy. Dtsch Arztebl Int 114:141-148

BfArM. Öffentlicher Bewertungsbericht MEDIKINET ADULT, 2011. https://portal.dimdi.de/amispb/doc/2011/07/25/2163890/OBFMB D5B836E01CC4AAA.rtf.

Biederman J, Mick E, Surman C, Doyle R et al (2006) A randomized, placebo-controlled trial of OROS methylphenidate in adults with attention-deficit/hyperactivity disorder. Biol Psychiatry 59:829-835

Bottelier MA, Schrantee A, Ferguson B, Tamminga HGH et al (2017) Age-dependent effects of acute methylphenidate on amygdala reactivity in stimulant treatment-naive patients with attention deficit/hyperactivity disorder. Psychiatry Res Neuroimaging. 269:36-42. https://doi.org/10.1016/j.pscychresns.2017.09.009

Bouffard R, Hechtman L, Minde K, Iaboni-Kassab F (2003) The efficacy of 2 different dosages of methylphenidate in treating adults with attention-deficit hyperactivity disorder. Can J Psychiatry 48:546-554

Chobanian AV, Bakris GL, Black HR, Cushman WC et al (2003) The Seventh Report of the Joint National Committee on Prevention, Detection, Evaluation, and Treatment of High Blood Pressure: the JNC 7 report. JAMA 289:2560-2572

de Zwaan M, Gruss B, Müller A, Graap H et al (2012) The estimated prevalence and correlates of adult ADHD in a German community sample. Eur Arch Psychiatry Clin Neurosci 262:79-86 
Ebert D, Krause J, Roth-Sackenheim C (2003) ADHS im Erwachsenenalter - Leitlinien auf der Basis eines Expertenkonsensus mit Unterstützung der DGPPN. Nervenarzt 74:939-946

Erskine HE, Norman RE, Ferrari AJ, Chan GC et al (2016) Long-term outcomes of attention-deficit/hyperactivity disorder and conduct disorder: a systematic review and meta-analysis. J Am Acad Child Adolesc Psychiatry 55:841-850

Faraone SV, Biederman J, Mick E (2006) The age-dependent decline of attention deficit hyperactivity disorder: a meta-analysis of followup studies. Psychol Med 36:159-165

Fields SA, Johnson WM, Hassig MB (2017) Adult ADHD: addressing a unique set of challenges. J Fam Pract 66:68-74

Fuermaier AB, Tucha L, Koerts J, Weisbrod M et al (2017) Effects of methylphenidate on memory functions of adults with ADHD. Appl Neuropsychol Adult 24:199-211

Harbour R, Miller J (2001) A new system for grading recommendations in evidence based guidelines. BMJ 323:334-336

Harpin VA (2005) The effect of ADHD on the life of an individual, their family, and community from preschool to adult life. Arch Dis Child 90(Suppl 1):i2-7

Health NCCfM (2009) Attention Deficit Hyperactivity Disorder: Diagnosis and Management of ADHD in Children, Young People and Adults. National Institute for Health and Clinical Excellence: Guidance. Leicester (UK), 2009

Insight health, prescription data 2019

IQVIA, prescription data NPI 2019.

Kabisch M, Ruckes C, Seibert-Grafe M, Blettner M (2011) Randomisierte kontrollierte Studien. Teil 17 der Serie zur Bewertung wissenschaftlicher Publikationen. Dtsch Arztebl Int 108:663-668

Katzman MA, Bilkey TS, Chokka PR, Fallu A, Klassen LJ (2017) Adult ADHD and comorbid disorders: clinical implications of a dimensional approach. BMC Psychiatry 17:302

Kessler RC, Adler LA, Gruber MJ, Sarawate CA et al (2007) Validity of the World Health Organization Adult ADHD Self-Report Scale (ASRS) Screener in a representative sample of health plan members. Int J Methods Psychiatr Res 16:52-65

Kooij JJ, Burger H, Boonstra AM, Van der Linden PD et al (2004) Efficacy and safety of methylphenidate in 45 adults with attentiondeficit/hyperactivity disorder. A randomized placebo-controlled double-blind cross-over trial. Psychol Med 34:973-982

Lam AP, Matthies S, Graf E, Colla M, Jacob C, Sobanski E, Alm B, Rösler M, Retz W, Retz-Junginger P, Kis B, Abdel-Hamid M, Müller HHO, Lücke C, Huss M, Jans T, Berger M, Tebartz van Elst L, Philipsen A (2019) Long-term effects of multimodal treatment on adult attention-deficit/hyperactivity disorder symptoms: follow-up analysis of the COMPAS trial. JAMA Netw Open. 2(5):e194980. https://doi.org/10.1001/jamanetworkopen .2019 .4980

Association of the Scientific Medical Societies (Arbeitsgemeinschaft der Wissenschaftlichen Medizinischen Fachgesellschaften, AWMF). Langfassung der interdisziplinären evidenz-und konsensbasierten S3 Leitline ADHS im Kindes-, Jugend-, Erwachsenenalter. AWMF-Registernummer 028-045. S3 guideline, long version. Published date: June 2018. Retrieved 7/7/2018 from https://www.awmf.org/uploads/tx_szleitlinien/028-0451_ S3_ADHS_2018-06.pdf

Mannuzza S, Klein RG, Bessler A, Malloy P, LaPadula M (1993) Adult outcome of hyperactive boys. Educational achievement, occupational rank, and psychiatric status. Arch Gen Psychiatry 50:565-576

Medice. Fachinformation Medikinet adult. Stand Januar 2017.

NICE guideline [NG87]. Attention deficit hyperactivity disorder: diagnosis and management. Published date: March 2018. Retrieved 4/4/2018 fromhttps://www.nice.org.uk/guidance/ng87
Philipsen A, Jans T, Graf E, Matthies S, Borel P, Colla M, Gentschow L, Langner D, Jacob C, Groß-Lesch S, Sobanski E, Alm B, Schumacher-Stien M, Roesler M, Retz W, Retz-Junginger P, Kis B, Abdel-Hamid M, Heinrich V, Huss M, Kornmann C, Bürger A, Perlov E, Ihorst G, Schlander M, Berger M, Tebartz van Elst L, Comparison of Methylphenidate, and Psychotherapy in Adult ADHD Study (COMPAS) Consortium (2015) Effects of group psychotherapy, individual counseling, methylphenidate, and placebo in the treatment of adult attention-deficit/hyperactivity disorder: a randomized clinical trial. JAMA Psychiatry 72(12):1199_ 1210. https://doi.org/10.1001/jamapsychiatry.2015.2146

Retz-Junginger P, Giesen L, Philipp-Wiegmann F, Rösler M, Retz W (2017) Der Wender-Reimherr-Selbstbeurteilungsfragebogen zur adulten ADHS. Nervenarzt 88:797-801

Retz W, Retz-Junginger P, Römer K, Rösler M (2013) Standardisierte Skalen zur strukturierten Diagnostik der ADHS im Erwachsenenalter. Fortschr Neurol Psychiatr 81:381-389

Retz W, Rösler M, Ose C, Scherag A et al (2012) Multiscale assessment of treatment efficacy in adults with ADHD: a randomized placebocontrolled, multi-centre study with extended-release methylphenidate. World J Biol Psychiatry 13:48-59

Röhrig B, du Prel JB, Wachtlin D, Blettner M (2009) Studientypen in der medizinischen Forschung. Teil 3 der Serie zur Bewertung wissenschaftlicher Publikationen. Dtsch Arztebl Int 106:262-268

Rösler M, Fischer R, Ammer R, Ose C, Retz W (2009) A randomised, placebo-controlled, 24-week, study of low-dose extended-release methylphenidate in adults with attention-deficit/hyperactivity disorder. Eur Arch Psychiatry Clin Neurosci 259:120-129

Rösler M, Ginsberg Y, Arngrim T, Adamou M et al (2013) Correlation of symptomatic improvements with functional improvements and patient-reported outcomes in adults with attention-deficit/hyperactivity disorder treated with OROS methylphenidate. World J Biol Psychiatry 14:282-290

Spencer T, Biederman J, Wilens T, Doyle R et al (2005) A large, double-blind, randomized clinical trial of methylphenidate in the treatment of adults with attention-deficit/hyperactivity disorder. Biol Psychiatry 57:456-463

Spencer T, Wilens T, Biederman J, Faraone SV et al (1995) A doubleblind, crossover comparison of methylphenidate and placebo in adults with childhood-onset attention-deficit hyperactivity disorder. Arch Gen Psychiatry 52:434-443

Spencer TJ, Biederman J, Mick E (2007) Attention-deficit/hyperactivity disorder: diagnosis, lifespan, comorbidities, and neurobiology. J Pediatr Psychol 32:631-642

Strauß M, Reif A, Ulke C, Paucke M, Sander C, Hegerl U, Weber H, Heupel J, Kopf J, Kittel-Schneider S (2019) Is brain arousal regulation a predictor of response to psychostimulant therapy in adult ADHD patients? Eur Arch Psychiatry Clin Neurosci. https ://doi.org/10.1007/s00406-019-01085-y

Thome J, Behnke K, Gleitz M, Steer L, Weiher M, Hasford J (2019) Quality and structure of outpatient care for adults with ADHD (attention deficit hyperactivity disorder)—results of the RAABE-Study. Psychiatr Prax. 46(6):317-323. https://doi. org/10.1055/a-0880-1804

Wender PH, Reimherr FW, Wood D, Ward M (1985) A controlled study of methylphenidate in the treatment of attention deficit disorder, residual type, in adults. Am J Psychiatry 142:547-552

Publisher's Note Springer Nature remains neutral with regard to jurisdictional claims in published maps and institutional affiliations. 